\title{
Generalized Common Fixed Point Results with Applications
}

\author{
Marwan Amin Kutbi, ${ }^{1}$ Muhammad Arshad, ${ }^{2}$ Jamshaid Ahmad, ${ }^{3}$ and Akbar Azam ${ }^{3}$ \\ ${ }^{1}$ Department of Mathematics, King Abdulaziz University, Jeddah, Saudi Arabia \\ ${ }^{2}$ Department of Mathematics \& Statistics, International Islamic University H-10, Islamabad, Pakistan \\ ${ }^{3}$ Department of Mathematics, COMSATS Institute of Information Technology, Chak Shahzad, Islamabad 44000, Pakistan
}

Correspondence should be addressed to Muhammad Arshad; marshad_zia@yahoo.com

Received 10 February 2014; Accepted 23 March 2014; Published 27 April 2014

Academic Editor: Ljubomir B. Ćirić

Copyright ( 2014 Marwan Amin Kutbi et al. This is an open access article distributed under the Creative Commons Attribution License, which permits unrestricted use, distribution, and reproduction in any medium, provided the original work is properly cited.

We obtained some generalized common fixed point results in the context of complex valued metric spaces. Moreover, we proved an existence theorem for the common solution for two Urysohn integral equations. Examples are presented to support our results.

\section{Introduction and Preliminaries}

Since the appearance of the Banach contraction mapping principle, a number of papers were dedicated to the improvement and generalization of that result. Most of these deal with the generalizations of the contractive condition in metric spaces.

Gähler [1] generalized the idea of metric space and introduced a 2-metric space which was followed by a number of papers dealing with this generalized space. Plenty of material is also available in other generalized metric spaces, such as, rectangular metric spaces, semimetric spaces, pseudometric spaces, probabilistic metric spaces, fuzzy metric spaces, quasimetric spaces, quasisemi metric spaces, $D$ metric spaces, $G$-metric space, partial metric space, and cone metric spaces (see [2-14]). Azam et al. [15] improved the Banach contraction principle by generalizing it in complex valued metric space involving rational inequity which could not be handled in cone metric spaces $[3,5,11,15]$ due to limitations regarding product and quotient. Rouzkard and Imdad [16] extended the work of Azam et al. [15]. Sintunavarat and Kumam [17] obtained common fixed point results by replacing constant of contractive condition to control functions. Recently, Klin-eam and Suanoom [12] extend the concept of complex valued metric spaces and generalized the results of Azam et al. [15] and Rouzkard and Imdad [16]. In this paper we continue the study of complex valued metric spaces and established some fixed point results for mappings satisfying a rational inequality. The idea of complex valued metric spaces can be exploited to define complex valued normed spaces and complex valued Hilbert spaces and then it will bring wonderful research activities in nonlinear analysis.

In this paper we continue our investigations initiated by Azam et al. [15] and prove a common fixed point result for two mappings and applied it to get the coincidence and common fixed points of three and four mappings.

We begin with listing some notations, definitions, and basic facts on these topics that we will need to convey our theorems. Let $\mathbb{C}$ be the set of complex numbers and $z_{1}, z_{2} \in$ $\mathbb{C}$. Define a partial order $\lesssim$ on $\mathbb{C}$ as follows:

$$
\text { iff } z_{1} \preccurlyeq z_{2}, \quad \operatorname{Re}\left(z_{1}\right) \leqslant \operatorname{Re}\left(z_{2}\right), \quad \operatorname{Im}\left(z_{1}\right) \leqslant \operatorname{Im}\left(z_{2}\right) .
$$

It follows that

$$
z_{1} \preccurlyeq z_{2}
$$

if one of the following conditions is satisfied:

$$
\begin{array}{ll}
\text { (i) } \operatorname{Re}\left(z_{1}\right)=\operatorname{Re}\left(z_{2}\right), & \operatorname{Im}\left(z_{1}\right)<\operatorname{Im}\left(z_{2}\right), \\
\text { (ii) } \operatorname{Re}\left(z_{1}\right)<\operatorname{Re}\left(z_{2}\right), & \operatorname{Im}\left(z_{1}\right)=\operatorname{Im}\left(z_{2}\right), \\
\text { (iii) } \operatorname{Re}\left(z_{1}\right)<\operatorname{Re}\left(z_{2}\right), & \operatorname{Im}\left(z_{1}\right)<\operatorname{Im}\left(z_{2}\right), \\
\text { (iv) } \operatorname{Re}\left(z_{1}\right)=\operatorname{Re}\left(z_{2}\right), & \operatorname{Im}\left(z_{1}\right)=\operatorname{Im}\left(z_{2}\right) .
\end{array}
$$


In particular, we will write $z_{1} \preccurlyeq z_{2}$ if $z_{1} \neq z_{2}$ and one of (i), (ii), and (iii) is satisfied and we will write $z_{1} \prec z_{2}$ if only (iii) is satisfied. Note that

$$
\begin{gathered}
0 \preceq z_{1} \precsim z_{2} \Longrightarrow\left|z_{1}\right|<\left|z_{2}\right|, \\
z_{1} \preceq z_{2}, \quad z_{2} \prec z_{3} \Longrightarrow z_{1} \prec z_{3} .
\end{gathered}
$$

Definition 1. Let $X$ be a nonempty set. Suppose that the selfmapping $d: X \times X \rightarrow \mathbb{C}$ satisfies:

(1) $0 \precsim d(x, y)$, for all $x, y \in X$ and $d(x, y)=0$ if and only if $x=y$;

(2) $d(x, y)=d(y, x)$ for all $x, y \in X$;

(3) $d(x, y) \precsim d(x, z)+d(z, y)$, for all $x, y, z \in X$.

Then $d$ is called a complex valued metric on $X$, and $(X, d)$ is called a complex valued metric space. A point $x \in X$ is called interior point of a set $A \subseteq X$ whenever there exists $0 \prec r \in \mathbb{C}$ such that

$$
B(x, r)=\{y \in X: d(x, y) \prec r\} \subseteq A \text {. }
$$

A point $x \in X$ is called a limit point of $A$ whenever for every $0 \prec r \in \mathbb{C}$,

$$
B(x, r) \cap(A \backslash\{x\}) \neq \phi .
$$

$A$ is called open whenever each element of $A$ is an interior point of $A$. Moreover, a subset $B \subseteq X$ is called closed whenever each limit point of $B$ belongs to $B$. The family

$$
F=\{B(x, r): x \in X, 0 \prec r\}
$$

is a subbasis for a Hausdorff topology $\tau$ on $X$.

Let $x_{n}$ be a sequence in $X$ and $x \in X$. If for every $c \in \mathbb{C}$ with $0 \prec c$ there is $n_{0} \in \mathbb{N}$ such that for all $n>n_{0}$, $d\left(x_{n}, x\right) \prec c$, then $\left\{x_{n}\right\}$ is said to be convergent, $\left\{x_{n}\right\}$ converges to $x$, and $x$ is the limit point of $\left\{x_{n}\right\}$. We denote this by $\lim _{n \rightarrow \infty} x_{n}=x$, or $x_{n} \rightarrow x$, as $n \rightarrow \infty$. If for every $c \in \mathbb{C}$ with $0 \prec c$ there is $n_{0} \in \mathbb{N}$ such that for all $n>n_{0}$, $d\left(x_{n}, x_{n+m}\right) \prec c$, then $\left\{x_{n}\right\}$ is called a Cauchy sequence in $(X, d)$. If every Cauchy sequence is convergent in $(X, d)$, then $(X, d)$ is called a complete complex valued metric space. Let $X$ be a nonempty set and $T, f: X \rightarrow X$. The mappings $T$, $f$ are said to be weakly compatible if they commute at their coincidence point (i.e., $T f x=f T x$ whenever $T x=f x$ ). A point $y \in X$ is called point of coincidence of $T$ and $f$ if there exists a point $x \in X$ such that $y=T x=f x$. We require the following lemmas.

Lemma 2 (see [15]). Let $(X, d)$ be a complex valued metric space and let $\left\{x_{n}\right\}$ be a sequence in $X$. Then $\left\{x_{n}\right\}$ converges to $x$ if and only if $\left|d\left(x_{n}, x\right)\right| \rightarrow 0$ as $n \rightarrow \infty$.

Lemma 3 (see [15]). Let $(X, d)$ be a complex valued metric space and let $\left\{x_{n}\right\}$ be a sequence in $X$. Then $\left\{x_{n}\right\}$ is a Cauchy sequence if and only if $\left|d\left(x_{n}, x_{n+m}\right)\right| \rightarrow 0$ as $n \rightarrow \infty$.
Definition 4 (see [18]). Two families of self-mappings $\left\{T_{i}\right\}_{1}^{m}$ and $\left\{S_{i}\right\}_{1}^{n}$ are said to be pairwise commuting if:

$$
\begin{aligned}
& \text { (1) } T_{i} T_{j}=T_{j} T_{i}, i, j \in\{1,2, \ldots, m\} ; \\
& \text { (2) } S_{k} S_{l}=S_{l} S_{k}, k, l \in\{1,2, \ldots, n\} ; \\
& \text { (3) } T_{i} S_{k}=S_{k} T_{i}, i \in\{1,2, \ldots, m\}, k \in\{1,2, \ldots, n\} .
\end{aligned}
$$

Lemma 5 (see [19]). Let $X$ be a nonempty set and $f: X \rightarrow X$ a function. Then there exists a subset $E \subset X$ such that $f E=f X$ and $f: E \rightarrow X$ is one to one.

Lemma 6 (see [20]). Let $X$ be a nonempty set and the mappings $S, T, f: X \rightarrow X$ have a unique point of coincidence $v$ in $X$. If $(S, f)$ and $(T, f)$ are weakly compatible, then $f v$ is a unique common fixed point of $S, T, f$.

\section{Main Results}

Theorem 7. Let $(X, d)$ be a complete complex valued metric space and $0 \leq h<1$. If the self-mappings $S, T: X \rightarrow X$ satisfy

$$
d(S x, T y) \lesssim h L(x, y)
$$

for all $x, y \in X$, where

$$
\begin{aligned}
& L(x, y) \\
& \quad \in\left\{d(x, y), d(x, S x), d(y, T y), \frac{d(x, S x) d(y, T y)}{1+d(x, y)}\right\}
\end{aligned}
$$

then $S$ and $T$ have a unique common fixed point.

Proof. We will first show that fixed point of one map is a fixed point of the other. Suppose that $p=T p$. Then from (8)

$$
d(S p, p)=d(S p, T p) \precsim h L(p, p) .
$$

Case 1

$$
d(S p, p) \lesssim h d(p, p)=0, \quad p=S p
$$

Case 2

$$
d(S p, p) \lesssim h d(p, S p),
$$

which yields that $p=S p$.

Case 3

$$
d(S p, p) \precsim h d(p, T p)=0, \quad p=S p .
$$

Case 4

$$
d(S p, p) \precsim h\left[\frac{d(p, S p) d(p, T p)}{1+d(p, p)}\right],
$$

which implies that $d(S p, p) \precsim 0$, and hence $p=S p$. In a similar manner it can be shown that any fixed point of $S$ is also the fixed point of $T$. Let $x_{0} \in X$ and define

$$
\begin{gathered}
x_{2 n+1}=S x_{2 n} \\
x_{2 n+2}=T x_{2 n+1}, \quad n \geq 0 .
\end{gathered}
$$


We will assume that $x_{n} \neq x_{n+1}$ for each $n$. Otherwise, there exists an $n$ such that $x_{2 n}=x_{2 n+1}$. Then $x_{2 n}=S x_{2 n}$ and $x_{2 n}$ is a fixed point of $S$, hence a fixed point of $T$. Similarly, if $x_{2 n+1}=$ $x_{2 n+2}$ for some $n$, then $x_{2 n+1}$ is common fixed point of $T$ and hence of $S$. From (8)

$$
d\left(x_{2 n+1}, x_{2 n+2}\right)=d\left(S x_{2 n}, T x_{2 n+1}\right) \leq h L\left(x_{2 n}, x_{2 n+1}\right) .
$$

Case 1

$$
\left|d\left(x_{2 n+1}, x_{2 n+2}\right)\right|=\left|d\left(S x_{2 n}, T x_{2 n+1}\right)\right| \leq h\left|d\left(x_{2 n}, x_{2 n+1}\right)\right| .
$$

Case 2

$$
\begin{aligned}
\left|d\left(x_{2 n+1}, x_{2 n+2}\right)\right| & =\left|d\left(S x_{2 n}, T x_{2 n+1}\right)\right| \\
& \leq h\left|d\left(x_{2 n}, S x_{2 n}\right)\right| \\
& =h\left|d\left(x_{2 n}, x_{2 n+1}\right)\right| .
\end{aligned}
$$

Case 3

$$
\begin{aligned}
\left|d\left(x_{2 n+1}, x_{2 n+2}\right)\right| & =\left|d\left(S x_{2 n}, T x_{2 n+1}\right)\right| \\
& \leq h\left|d\left(x_{2 n+1}, T x_{2 n+1}\right)\right| \\
& =h\left|d\left(x_{2 n+1}, x_{2 n+2}\right)\right|,
\end{aligned}
$$

which implies that

$$
x_{2 n+1}=x_{2 n+2},
$$

a contradiction to our assumption.

Case 4

$$
\begin{aligned}
\left|d\left(x_{2 n+1}, x_{2 n+2}\right)\right| & =\left|d\left(S x_{2 n}, T x_{2 n+1}\right)\right| \\
& \leq h\left|\frac{d\left(x_{2 n}, S x_{2 n}\right) d\left(x_{2 n+1}, T x_{2 n+1}\right)}{1+d\left(x_{2 n}, x_{2 n+1}\right)}\right| \\
& \leq h\left|\frac{d\left(x_{2 n}, x_{2 n+1}\right)}{1+d\left(x_{2 n}, x_{2 n+1}\right)}\right|\left|d\left(x_{2 n+1}, x_{2 n+2}\right)\right| \\
& \leq h\left|d\left(x_{2 n+1}, x_{2 n+2}\right)\right| .
\end{aligned}
$$

That is

$$
x_{2 n+1}=x_{2 n+2},
$$

a contradiction to our assumption.

Thus, $\left|d\left(x_{2 n+1}, x_{2 n+2}\right)\right| \leq h\left|d\left(x_{2 n}, x_{2 n+1}\right)\right|$. Similarly, one can show that $\left|d\left(x_{2 n+2}, x_{2 n+3}\right)\right| \leq h\left|d\left(x_{2 n+1}, x_{2 n+2}\right)\right|$. It follows that, for all $n$,

$$
\begin{aligned}
\left|d\left(x_{n}, x_{n+1}\right)\right| & \leq h\left|d\left(x_{n-1}, x_{n}\right)\right| \\
& \leq h^{2}\left|d\left(x_{n-2}, x_{n-1}\right)\right| \leq \cdots \leq h^{n}\left|d\left(x_{0}, x_{1}\right)\right| .
\end{aligned}
$$

Now for any $m>n$,

$$
\begin{aligned}
\left|d\left(x_{m}, x_{n}\right)\right| \leq & \left|d\left(x_{n}, x_{n+1}\right)\right|+\left|d\left(x_{n+1}, x_{n+2}\right)\right| \\
& +\cdots+\left|d\left(x_{m-1}, x_{m}\right)\right| \\
\leq & {\left[h^{n}+h^{n+1}+\cdots+h^{m-1}\right]\left|d\left(x_{0}, x_{1}\right)\right| } \\
\leq & {\left[\frac{h^{n}}{1-h}\right]\left|d\left(x_{0}, x_{1}\right)\right| }
\end{aligned}
$$

and so

$$
\left|d\left(x_{m}, x_{n}\right)\right| \leq \frac{h^{n}}{1-h}\left|d\left(x_{0}, x_{1}\right)\right| \longrightarrow 0, \quad \text { as } m, n \longrightarrow \infty .
$$

This implies that $\left\{x_{n}\right\}$ is a Cauchy sequence. Since $X$ is complete, there exists $u \in X$ such that $x_{n} \rightarrow u$. It follows that $u=S u$; otherwise $d(u, S u)=z>0$ and we would then have

$$
\begin{aligned}
z & \lessgtr d\left(u, x_{2 n+2}\right)+d\left(x_{2 n+2}, S u\right) \\
& \lessgtr d\left(u, x_{2 n+2}\right)+d\left(T x_{2 n+1}, S u\right) \\
& \lessgtr d\left(u, x_{2 n+2}\right)+h L\left(u, x_{2 n+1}\right) .
\end{aligned}
$$

Case 1

$$
|z| \leq\left|d\left(u, x_{2 n+2}\right)\right|+h\left|d\left(u, x_{2 n+1}\right)\right| .
$$

That is, $|z| \leq 0$, a contradiction and hence $u=S u$.

Case 2

$$
|z| \leq\left|d\left(u, x_{2 n+2}\right)\right|+h|d(u, S u)| .
$$

That is, $|z| \leq 0$, a contradiction and hence $u=S u$.

Case 3

$$
\begin{aligned}
|z| & \leq\left|d\left(u, x_{2 n+2}\right)\right|+h\left|d\left(x_{2 n+1}, T x_{2 n+1}\right)\right| \\
& \leq\left|d\left(u, x_{2 n+2}\right)\right|+h\left|d\left(x_{2 n+1}, x_{2 n+2}\right)\right| \\
& \leq\left|d\left(u, x_{2 n+2}\right)\right|+h^{2 n+2}\left|d\left(x_{0}, x_{1}\right)\right| .
\end{aligned}
$$

This in turn gives us $|z| \leq 0$, a contradiction and hence $u=$ Su.

Case 4

$$
\begin{aligned}
|z| & \leq\left|d\left(u, x_{2 n+2}\right)\right|+h\left|\frac{d(u, S u) d\left(x_{2 n+1}, T x_{2 n+1}\right)}{1+d\left(u, x_{2 n+1}\right)}\right| \\
& \leq d\left(u, x_{2 n+2}\right)+h \frac{|d(u, S u)|\left|d\left(x_{2 n+1}, x_{2 n+2}\right)\right|}{\left|1+d\left(u, x_{2 n+1}\right)\right|} \\
& \leq\left|d\left(u, x_{2 n+2}\right)\right|+h^{2 n+2} \frac{|d(u, S u)|\left|d\left(x_{0,}, x_{1}\right)\right|}{\left|1+d\left(u, x_{2 n+1}\right)\right|} .
\end{aligned}
$$

That is, $|z| \leq 0$ and hence $u=S u$. It follows similarly that $u=$ $T u$. We now show that $S$ and $T$ have unique common fixed 
point. For this, assume that $u^{*}$ in $X$ is another common fixed point of $S$ and $T$. Then $d\left(u, u^{*}\right)=d\left(S u, T u^{*}\right) \lesssim h L\left(u, u^{*}\right)$.

Case 1

$$
d\left(u, u^{*}\right) \precsim h d\left(u, u^{*}\right)
$$

Case 2

$$
d\left(u, u^{*}\right) \precsim h d(u, S u) \precsim h d(u, u)=0 .
$$

This gives us $u=u^{*}$.

Case 3

$$
d\left(u, u^{*}\right) \precsim h d\left(u^{*}, T u^{*}\right)=h d\left(u^{*}, u^{*}\right)=0 .
$$

Case 4

$$
d\left(u, u^{*}\right) \precsim \frac{h d(u, S u) d\left(u^{*}, T u^{*}\right)}{1+d\left(u, u^{*}\right)}=0 .
$$

Hence, in all cases $u^{*}=u$. This completes the proof of the theorem.

Corollary 8 (see [15]). Let $(X, d)$ be a complete complex valued metric space and let $S, T: X \rightarrow X$ and $0<h<1$. If the self-mappings $S$, Tsatisfy

$$
d(S x, T y) \lesssim h L(x, y)
$$

for all $x, y \in X$, where

$$
L(x, y) \in\left\{d(x, y), \frac{d(x, S x) d(y, T y)}{1+d(x, y)}\right\},
$$

then $S$ and $T$ have a unique common fixed point.

Corollary 9. Let $(X, d)$ be a complete complex valued metric space and $0 \leq h<1$. If the self-mapping $T: X \rightarrow X$ satisfies

$$
d(T x, T y) \precsim h L(x, y)
$$

for all $x, y \in X$, where

$$
\begin{aligned}
& L(x, y) \\
& \quad \in\left\{d(x, y), d(x, T x), d(y, T y), \frac{d(x, T x) d(y, T y)}{1+d(x, y)}\right\}
\end{aligned}
$$

then $T$ has a unique fixed point.

Corollary 10 (see [15]). Let $(X, d)$ be a complete complex valued metric space and let $T: X \rightarrow X$ and $0 \leq h<1$. If the self-mapping Tsatisfies

$$
d(T x, T y) \lesssim h L(x, y)
$$

for all $x, y \in X$, where

$$
L(x, y) \in\left\{d(x, y), \frac{d(x, T x) d(y, T y)}{1+d(x, y)}\right\},
$$

then $T$ has a unique fixed point.
As an application of Theorem 7, we prove the following theorem for two finite families of mappings.

Theorem 11. If $\left\{T_{i}\right\}_{1}^{m}$ and $\left\{S_{i}\right\}_{1}^{n}$ are two finite pairwise commuting finite families of self-mapping defined on a complete complex valued metric space $(X, d)$ such that the mappings $S$ and $T$ (with $T=T_{1}, T_{2}, \ldots, T_{m}$ and $S=S_{1}, S_{2}, \ldots, S_{n}$ ) satisfy the contractive condition (8), then the component maps of the two families $\left\{T_{i}\right\}_{1}^{m}$ and $\left\{S_{i}\right\}_{1}^{n}$ have a unique common fixed point.

Proof. From theorem we can say that the mappings $T$ and $S$ have a unique common fixed point $z$; that is, $T z=S z=z$. Now our requirement is to show that $z$ is a common fixed point of all the component mappings of both families. In view of pairwise commutativity of the families $\left\{T_{i}\right\}_{1}^{m}$ and $\left\{S_{i}\right\}_{1}^{n}$, (for every $1 \leq k \leq m$ ) we can write $T_{k} z=T_{k} T z=T T_{k} z$ and $T_{k} z=T_{k} S z=S T_{k} z$ which show that $T_{k} z$ (for every $k$ ) is also a common fixed point of $T$ and $S$. By using the uniqueness of common fixed point, we can write $T_{k} z=z$ (for every $k$ ) which shows that $z$ is a common fixed point of the family $\left\{T_{i}\right\}_{1}^{m}$. Using the same argument one can also show that (for every $1 \leq k \leq n) S_{k} z=z$. Thus component maps of the two families $\left\{T_{i}\right\}_{1}^{m}$ and $\left\{S_{i}\right\}_{1}^{n}$ have a unique common fixed point.

By setting $T_{1}=T_{2}=\cdots=T_{m}=F$ and $S_{1}=S_{2}=\cdots=$ $S_{n}=G$, in Theorem 11, we get the following corollary.

Corollary 12. If $F$ and $G$ are two commuting self-mappings defined on a complete complex valued metric space $(X, d)$ satisfying the condition

$$
d\left(F^{m} x, G^{n} y\right) \lesssim h L(x, y)
$$

for all $x, y \in X$ and $0 \leq h<1$, where

$$
\begin{gathered}
L(x, y) \in\left\{d(x, y), d\left(x, F^{m} x\right), d\left(y, G^{n} y\right),\right. \\
\left.\frac{d\left(x, F^{m} x\right) d\left(y, G^{n} y\right)}{1+d(x, y)}\right\},
\end{gathered}
$$

then $F$ and $G$ have a unique common fixed point.

Corollary 13. Let $(X, d)$ be a complete complex valued metric space and let $T: X \rightarrow X$ be a self-mapping satisfying

$$
d\left(T^{n} x, T^{n} y\right) \precsim h L(x, y)
$$

for all $x, y \in X$ and $0 \leq h<1$, where

$$
\begin{gathered}
L(x, y) \in\left\{d(x, y), d\left(x, T^{m} x\right), d\left(y, T^{n} y\right),\right. \\
\left.\frac{d\left(x, T^{n} x\right) d\left(y, T^{n} y\right)}{1+d(x, y)}\right\} .
\end{gathered}
$$

Then $T$ has a unique fixed point.

Corollary 14 (see $[15])$. Let $(X, d)$ be a complete complex valued metric space and $T: X \rightarrow X$ and $0 \leq h<1$. The self-mapping $T$ satisfies

$$
d\left(T^{n} x, T^{n} y\right) \precsim h L(x, y)
$$


for all $x, y \in X$, where

$$
L(x, y) \in\left\{d(x, y), \frac{d\left(x, T^{n} x\right) d\left(y, T^{n} y\right)}{1+d(x, y)}\right\}
$$

\section{Then $T$ has a unique fixed point.}

Our next example exhibits the superiority of Corollary 13 over Corollary 9.

Example 15. Let $X_{1}=\{z \in \mathbb{C}: 0 \leq \operatorname{Re} z \leq 1, \operatorname{Im} z=0\}$ and $X_{2}=\{z \in \mathbb{C}: 0 \leq \operatorname{Im} z \leq 1, \operatorname{Re} z=0\}$ and let $X=X_{1} \cup X_{2}$. Then with $z=x+i y$, set $S=T$ and define $T: X \rightarrow X$ as follows:

$$
T(x, y)= \begin{cases}(0,0) & \text { if } x, y \in Q \\ (1,0) & \text { if } x \in Q^{c}, y \in Q \\ (0,1) & \text { if } x \in Q, y \in Q^{c} \\ (1,1) & \text { if } x, y \in Q^{c} .\end{cases}
$$

Consider a complex valued metric $d: X \times X \rightarrow \mathbb{C}$ as follows:

$$
d\left(z_{1}, z_{2}\right)= \begin{cases}\frac{2 i}{3}\left|x_{1}-x_{2}\right|, & \text { if } z_{1}, z_{2} \in X_{1} \\ \frac{i}{3}\left|y_{1}-y_{2}\right|, & \text { if } z_{1}, z_{2} \in X_{2} \\ i\left(\frac{2}{3} x_{1}+\frac{1}{3} y_{2}\right), & \text { if } z_{1} \in X_{1}, z_{2} \in X_{2} \\ i\left(\frac{1}{3} y_{1}+\frac{2}{3} x_{2}\right) & \text { if } z_{1} \in X_{2}, z_{2} \in X_{1},\end{cases}
$$

where $z_{1}=x_{1}+i y_{1}, z_{2}=x_{2}+i y_{2} \in X$. Then $(X, d)$ is a complete complex valued metric space. By a routine calculation, one can verify that the map $T^{2}$ satisfies condition (43) with $\lambda=(1 / 3)$ (say). It is interesting to notice that this example cannot be covered by Corollary 9 as $z_{1}=(1,0)$, $z_{2}=(1 / 2,0) \in X$ implies

$$
\frac{2 i}{3}=d\left(T z_{1}, T z_{2}\right) \leq d\left(z_{1}, z_{2}\right)=\frac{i}{3}
$$

a contradiction for every choice of $\lambda$ which amounts to say that condition (37) is not satisfied. Notice that the point $0 \in X$ remains fixed under $T$ and $T^{2}$ and is indeed unique.

\section{Application}

By providing the following result, we establish an existence theorem for the common solution for two Urysohn integral equations.

Theorem 16. Let $X=C\left([a, b], \mathbb{R}^{n}\right), a>0$, and $d: X \times X \rightarrow$ $\mathbb{C}$ is defined as follows:

$$
d(x, y)=\max _{t \in[a, b]}\|x(t)-y(t)\|_{\infty} \sqrt{1+a^{2}} e^{i \tan ^{-1} a} .
$$

Consider the Urysohn integral equations

$$
\begin{aligned}
& x(t)=\int_{a}^{b} K_{1}(t, s, x(s)) d s+g(t), \\
& x(t)=\int_{a}^{b} K_{2}(t, s, x(s)) d s+h(t),
\end{aligned}
$$

where $\in[a, b] \subset \mathbb{R}, x, g, h \in X$.

Suppose that $K_{1}, K_{2}:[a, b] \times[a, b] \times \mathbb{R}^{n} \rightarrow \mathbb{R}^{n}$ are such that $F_{x}, G_{x} \in X$ for each $x \in X$, where,

$$
\begin{gathered}
F_{x}(t)=\int_{a}^{b} K_{1}(t, s, x(s)) d s \\
G_{x}(t)=\int_{a}^{b} K_{2}(t, s, x(s)) d s, \quad \forall t \in[a, b] .
\end{gathered}
$$

If there exists $0 \leq h<1$ such that for every $x, y \in X$

$$
\begin{aligned}
& \left\|F_{x}(t)-G_{y}(t)+g(t)-h(t)\right\|_{\infty} \sqrt{1+a^{2}} e^{i \tan ^{-1} a} \\
& \quad \precsim h L(x, y)(t),
\end{aligned}
$$

where

$$
\begin{aligned}
& L(x, y)(t) \\
& \in\{A(x, y)(t), B(x, y)(t), C(x, y)(t), D(x, y)(t)\}, \\
& A(x, y)(t)=\|x(t)-y(t)\|_{\infty} \sqrt{1+a^{2}} e^{i \tan ^{-1} a}, \\
& B(x, y)(t)=\left\|F_{x}(t)+g(t)-x(t)\right\|_{\infty} \sqrt{1+a^{2}} e^{i \tan ^{-1} a}, \\
& C(x, y)(t)=\left\|G_{y}(t)+h(t)-y(t)\right\|_{\infty} \sqrt{1+a^{2}} e^{i \tan ^{-1} a}, \\
& D(x, y)(t) \\
& =\frac{\left\|F_{x}(t)+g(t)-x(t)\right\|_{\infty}\left\|G_{y}(t)+h(t)-y(t)\right\|_{\infty}}{1+\max _{t \in[a, b]} A(x, y)(t)} \\
& \quad \times \sqrt{1+a^{2}} e^{i \tan ^{-1} a},
\end{aligned}
$$

then the system of integral equations $(\alpha)$ and $(\beta)$ has a unique common solution.

Proof. Define $S, T: X \rightarrow X$ by

$$
S x=F_{x}+g, \quad T x=G_{x}+h .
$$


Then

$$
\begin{gathered}
d(S x, T y)=\max _{t \in[a, b]}\left\|F_{x}(t)-G_{y}(t)+g(t)-h(t)\right\|_{\infty} \\
\quad \times \sqrt{1+a^{2}} e^{i \tan ^{-1} a}, \\
d(x, y)=\max _{t \in[a, b]} A(x, y)(t), \\
d(x, S x)=\max _{t \in[a, b]} B(x, y)(t), \\
d(y, T y)=\max _{t \in[a, b]} C(x, y)(t), \\
\frac{d(x, S x) d(y, T y)}{1+d(x, y)}=\max _{t \in[a, b]} D(x, y)(t) .
\end{gathered}
$$

It is easily seen that $d(S x, T y) \precsim h L(x, y)$, where

$$
\begin{aligned}
& L(x, y) \\
& \quad \in\left\{d(x, y), d(x, S x), d(y, T y), \frac{d(x, S x) d(y, T y)}{1+d(x, y)}\right\}
\end{aligned}
$$

for every $x, y \in X$. By Theorem 7, the Urysohn integral equations $(\alpha)$ and $(\beta)$ have a unique common solution.

Remark 17. Now we will apply techniques of [6] to obtain the common fixed points of three and four mappings by using a common fixed point result for two mappings.

Theorem 18. Let $(X, d)$ be a complete complex valued metric space and $0 \leq h<1$. Let $S, T, f: X \rightarrow X$ by the self-mappings such that $S X \cup T X \subset f X$. Assume that the following holds:

$$
d(S x, T y) \precsim h L(x, y)
$$

for all $x, y \in X$, where

$$
\begin{gathered}
L(x, y) \in\{d(f x, f y), d(f x, S x), d(f y, T y), \\
\left.\frac{d(f x, S x) d(f y, T y)}{1+d(f x, f y)}\right\} .
\end{gathered}
$$

If $(S, f)$ and $(T, f)$ are weakly compatible and $f X$ is closed, then $S, T$, and $f$ have a unique common fixed point in $X$.

Proof. By Lemma 5, there exists $E \subset X$ such that $f E=f X$ and $f: E \rightarrow X$ is one to one. Now define the self-mappings $g, h: f E \rightarrow f E$ by $g(f x)=S x$ and $h(f x)=T x$, respectively. Since $f$ is one to one on $E$, then $g, h$ are well defined. Note that

$$
d(g(f x), h(f x)) \precsim h L(x, y)
$$

where

$$
\begin{gathered}
L(x, y) \in\{d(f x, f y), d(f x, g(f x)), d(f y, h(f y)), \\
\left.\frac{d(f x, g(f x)) d(f y, h(f y))}{1+d(f x, f y)}\right\} .
\end{gathered}
$$

By Theorem 7 as $f E$ is complete, we deduce that there exists a unique common fixed point $f z \in f E$ of $g$ and $h$; that is, $f z=g(f z)=h(f z)$. Thus, $z$ is a coincidence point of $S$, $T$, and $f$. Now we show that $S, T$, and $f$ have unique point of coincidence. Now let $x \in X$ such that $S x=T x=f x$, $f x \neq f z$. Then $f x$ is another common fixed point of $g$ and $h$, which is a contradiction, which implies that $S, T$, and $f$ have a unique point of coincidence. Since $(S, f)$ and $(T, f)$ are weakly compatible by Lemma 6 , we deduce that $f z$ is a unique common fixed point of $S, T$, and $f$.

Theorem 19. Let $(X, d)$ be a complete complex valued metric space and $0 \leq h<1$. Let $S, T, f, g: X \rightarrow X$ by the selfmappings such that $S X, T X \subset f X=g X$. Assume that the following holds:

$$
d(S x, T y) \precsim h L(x, y)
$$

for all $x, y \in X$, where

$$
\begin{gathered}
L(x, y) \in\{d(f x, g y), d(f x, S x), d(g y, T y), \\
\left.\frac{d(f x, S x) d(g y, T y)}{1+d(f x, g y)}\right\} .
\end{gathered}
$$

If $(S, f)$ and $(T, g)$ are weakly compatible and $f X$ is closed in $X$, then $S, T, f$, and $g$ have a unique common fixed point in $X$.

Proof. By Lemma 5, there exists $E_{1}, E_{2} \subset X$ such that $f E_{1}=$ $f X=g X=g E_{2}, f: E_{1} \rightarrow X, g: E_{2} \rightarrow X$ are one to one. Now define the mappings $A, B: f E_{1} \rightarrow f E_{1}$ by $A f(x)=S x$ and $B g(x)=T x$, respectively. Since $f, g$ are one to one on $E_{1}$ and $E_{2}$, respectively, then the mappings $A, B$ are well-defined. Now

$$
d(S x, T y)=d(A(f x), B(g y)) \lesssim h L(x, y),
$$

where

$$
\begin{aligned}
& L(x, y) \\
& \qquad\{\{d(f x, g y), d(f x, A(f x)), d(g y, B(g y)), \\
& \left.\quad \frac{d(f x, A(f x)) d(g y, B(g y))}{1+d(f x, g y)}\right\}
\end{aligned}
$$

for all $f x, g y \in f E_{1}$. By Theorem 7, as $f E_{1}$ is complete subspace of $X$, we deduce that there exists a unique common fixed point $f z \in f E_{1}$ of $A$ and $B$; that is, $A(f z)=B f(z)=f z$. 
This implies that $S z=f z$; let $v \in X$ such that $f z=g v$. We have $B(g v)=g v \Rightarrow T v=g v$. We show that $S$ and $f$ have a unique point of coincidence. If $S w=f w$ then $f w$ is a fixed point of $A$. By the proof of Theorem $7 f w$ is another common fixed point of $A$ and $B$ which is a contradiction. Hence, $S$ and $f$ have a unique point of coincidence. By Lemma 6 , it follows that $f z$ is a unique common fixed point of $S$ and $f$. Similarly, $g v$ is the unique common fixed point for $T$ and $g$. This proves that $f z=g v$ is the unique common fixed point for $S, T, f$, and $g$.

\section{Conflict of Interests}

The authors declare that there is no conflict of interests regarding the publication of this paper.

\section{Authors' Contribution}

All authors contributed equally and significantly in writing this paper. All authors read and approved the final paper.

\section{Acknowledgments}

This paper is dedicated to Professor Miodrag Mateljević on the occasion of his 65th birthday. The first author gratefully acknowledges the support from the Deanship of Scientific Research (DSR) at King Abdulaziz University (KAU) during this research. The third author gratefully acknowledges the support from the Higher Education Commission of Pakistan.

\section{References}

[1] S. Gähler, "2-metrische raume und ihre topologische strukture," Mathematische Nachrichten, vol. 26, pp. 115-148, 1963.

[2] M. Abbas, B. Fisher, and T. Nazir, "Well-Posedness and periodic point property of mappings satisfying a rational inequality in an ordered complex valued metric space," Numerical Functional Analysis and Optimization, vol. 243, p. 32, 2011.

[3] M. Abbas and B. E. Rhoades, "Fixed and periodic point results in cone metric spaces," Applied Mathematics Letters, vol. 22, no. 4, pp. 511-515, 2009.

[4] J. Ahmad, C. Klin-Eam, and A. Azam, "Common fixed points for multivalued mappings in complex valued metric spaces with applications," Abstract and Applied Analysis, vol. 2013, Article ID 854965, 12 pages, 2013.

[5] M. Arshad, A. Azam, and P. Vetro, "Some common fixed point results in cone metric spaces," Fixed Point Theory and Applications, vol. 2009, Article ID 493965, 11 pages, 2009.

[6] C. di Bari and P. Vetro, "Common fixed pointsfor three or four mappings via common fixed point for two mappings," http://arxiv.org/abs/1302.3816.

[7] Lj. Cirić, A. Razani, S. Radenović, and J. S. Ume, "Common fixed point theorems for families of weakly compatible maps," Computers \& Mathematics with Applications, vol. 55, no. 11, pp. 2533-2543, 2008.

[8] Lj. Cirić, "A generalization of Banach's contraction principle," Proceedings of the American Mathematical Society, vol. 45, pp. 267-273, 1974.
[9] Lj. Cirić, N. Hussain, and N. Cakić, "Common fixed points for Cirić type $f$-weak contraction with applications," Publicationes Mathematicae Debrecen, vol. 76, no. 1-2, pp. 31-49, 2010.

[10] Lj. Cirić, M. Abbas, R. Saadati, and N. Hussain, "Common fixed points of almost generalized contractive mappings in ordered metric spaces," Applied Mathematics and Computation, vol. 217, no. 12, pp. 5784-5789, 2011.

[11] L.-G. Huang and X. Zhang, "Cone metric spaces and fixed point theorems of contractive mappings," Journal of Mathematical Analysis and Applications, vol. 332, no. 2, pp. 1468-1476, 2007.

[12] C. Klin-eam and C. Suanoom, "Some common fixed-point theorems for generalized-contractive-type mappings on complexvalued metric spaces," Abstract and Applied Analysis, vol. 2013, Article ID 604215, 6 pages, 2013.

[13] M. A. Kutbi, J. Ahmad, and A. Azam, "On fixed points of $\alpha$ $\psi$-contractive multivalued mappings in cone metric spaces," Abstract and Applied Analysis, vol. 2013, Article ID 313782, 6 pages, 2013.

[14] M. A. Kutbi, A. Azam, J. Ahmad, and C. Di Bari, "Some common coupled fixed point results for generalized contraction in complex-valued metric spaces," Journal of Applied Mathematics, vol. 2013, Article ID 352927, 10 pages, 2013.

[15] A. Azam, B. Fisher, and M. Khan, "Common fixed point theorems in complex valued metric spaces," Numerical Functional Analysis and Optimization, vol. 32, no. 3, pp. 243-253, 2011.

[16] F. Rouzkard and M. Imdad, "Some common fixed point theorems on complex valued metric spaces," Computers \& Mathematics with Applications, vol. 64, no. 6, pp. 1866-1874, 2012.

[17] W. Sintunavarat and P. Kumam, "Generalized common fixed point theorems in complex valued metric spaces and applications," Journal of Inequalities and Applications, vol. 2012, article 84, 2012.

[18] M. Imdad, J. Ali, and M. Tanveer, "Coincidence and common fixed point theorems for nonlinear contractions in Menger PM spaces," Chaos, Solitons \& Fractals, vol. 42, no. 5, pp. 3121-3129, 2009.

[19] R. H. Haghi, Sh. Rezapour, and N. Shahzad, "Some fixed point generalizations are not real generalizations," Nonlinear Analysis. Theory, Methods \& Applications A, vol. 74, no. 5, pp. 1799-1803, 2011.

[20] A. Azam and M. Arshad, "Common fixed points of generalized contractive maps in cone metric spaces," Iranian Mathematical Society. Bulletin, vol. 35, no. 2, pp. 255-264, 2009. 


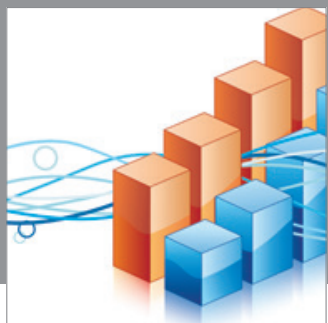

Advances in

Operations Research

mansans

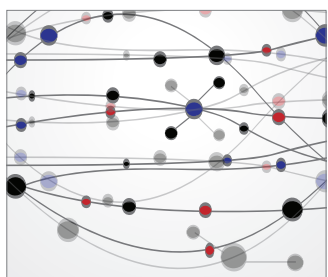

The Scientific World Journal
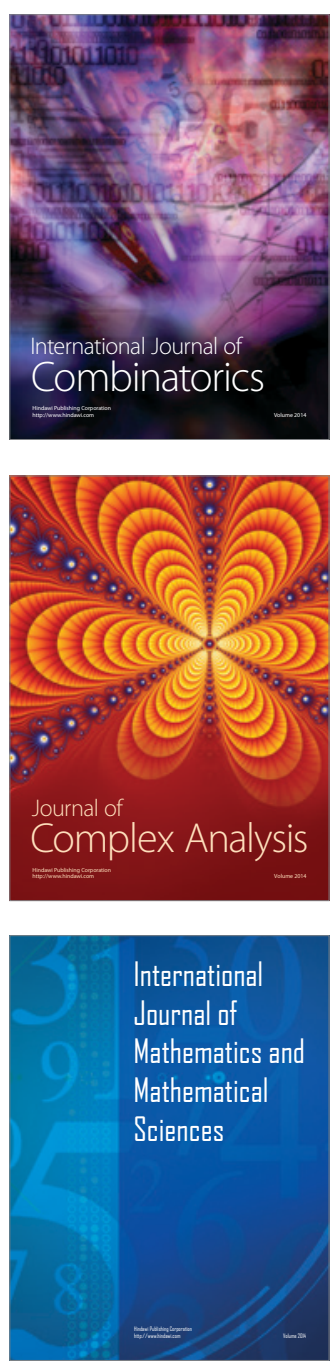
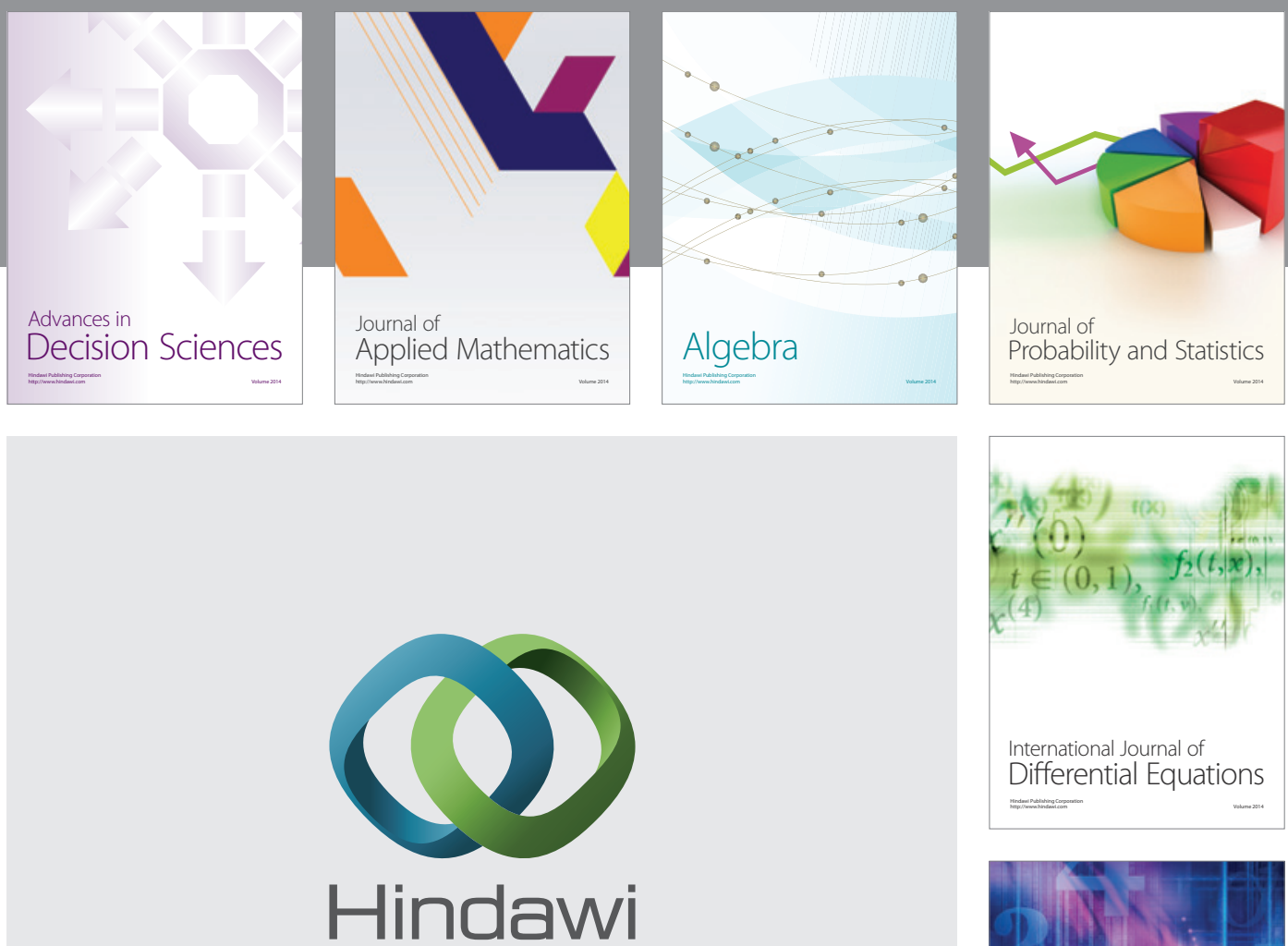

Submit your manuscripts at http://www.hindawi.com
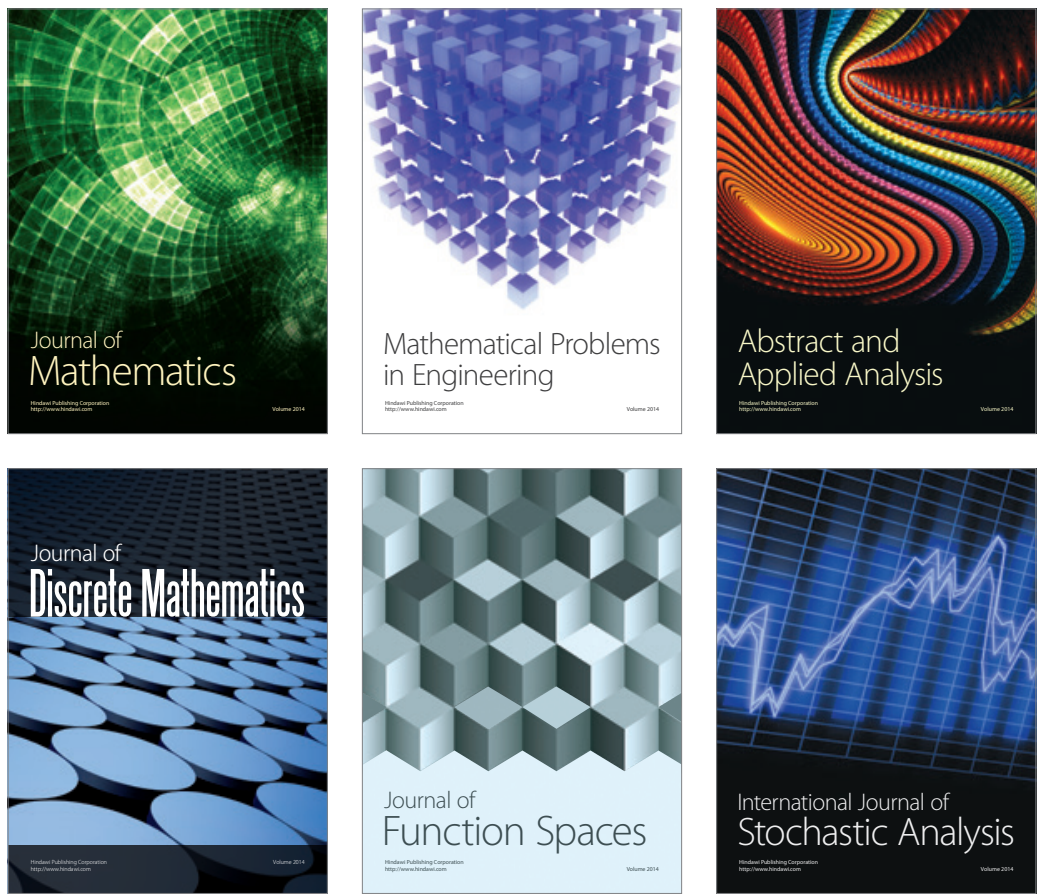

Journal of

Function Spaces

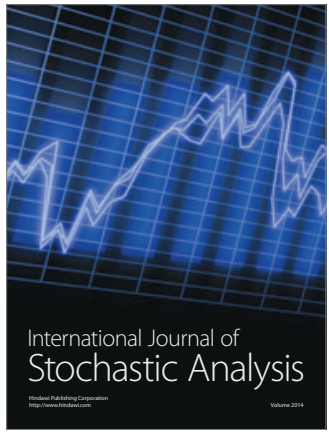

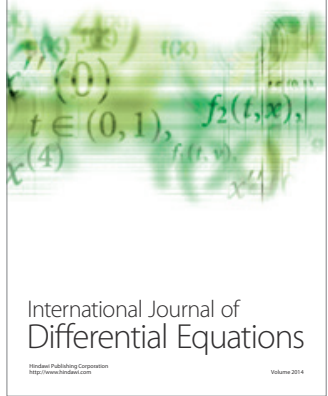
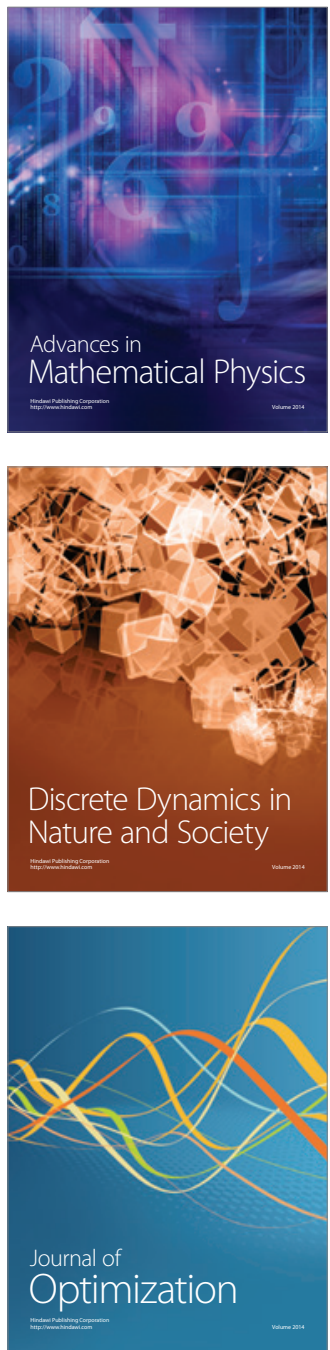